\title{
Analysis of Effect of the Community Based Physical Fitness Program for the Aged in an Isolated Island, Japan -An Application of the "Active Centenarian Physical Fitness Program (Iki-iki hyaku-sai Taiso)"-
}

\author{
Junko Yano ${ }^{1)}$, Kazuyo Sakai ${ }^{2)}$, Haruhisa Ibayashi ${ }^{1)}$, Masayuki Tanaka'), Truong-Minh Pham ${ }^{1)}$, \\ Tomohiro Nishiyama ${ }^{3)}$, Shinya Matsuda ${ }^{1)}$, Atsushi Kobayashi ${ }^{4)}$, Naonori Yakura ${ }^{4}$ \\ 1)Department of Preventive Medicine and Community Health, University of Occupational and Environmental Health \\ ${ }^{2)}$ Community Integrated Support Center, Nakatane-cho, Kumage-gun, Kagoshima-ken \\ ${ }^{3)}$ Omori Health Care Center, Hitachi Totsuka General Hospital, Hitachi Ltd. \\ ${ }^{4)}$ Sompo Japan Research Institute
}

\begin{abstract}
In order to test the usefulness of non-machine based physical fitness program, so called "Active centenarian physical fitness program", the authors have applied this program in an isolated island of Kagoshima. The participants were the 18 slightly frail elderly more than 65 years old (4 males and 14 females). The average age was $78.17 \pm 4.18$ years old (min: 71 , max: 85 years old). The main exercises continues about 30 minutes composing of: (1) Raises arms to back (2) Raises arms to sideways (3) Bending and extending knees (4) Standing up from chair (5) Extending knees (6) Raising legs to back (7) Raising legs to horizontal. After the 12 weeks intervention, improvement was observed for most of the physical fitness tests. So far as lifestyle, mental status and IADL were concerned, there were improvement observed in social role, intellectual activeness, outdoor activity, and hobby activity. Compared with the machine-based physical fitness program, the Active centenarian physical fitness program has more merits for application in the community setting, i.e. cheaper cost, easiness to master, safer physical activity.
\end{abstract}

Key words: physical fitness program, the frail elderly, health promotion community

\section{Introduction}

In order to support the increasing number of frail aged and their family, the Japanese government has introduced the Long Term Care Insurance (LTCI) in 2000. The new public insurance system has been welcomed by citizen, and as a results number of persons who received the LTCI services largely increased. This naturally causes a rapid increase in LTCI expen-

Received: December 3, 2007

Accepted: December 21, 2007

Correspondence: J. Yano, Department of Preventive Medicine and Community Health, University of Occupational and Environmental Health, Iseigaoka 1-1, Yahatanishi-ku, Kitakyushu, Fukuoka 807-8555, Japan

e-mail: yanoj@med.uoeh-u.ac.jp ditures and premium.

In 2006, the Ministry of Health, Labour and Welfare (MHLW) amended the LTCI law in order to make the scheme sustainable. The most important point is that the new system puts more importance on the preventive ADL services. Formerly, there were 6 eligibility levels from assistance required, care required level 1 to level 5. Under the new system, former "assistance required" is renamed "assistance required level 1", and former "care required level 1" was divided into "assistance required level 2" and "care required level 1". In the case of assistance required level 1 and 2, they have to receive the preventive ADL services. As the musculo-skeltal weakness is the most important reason of receiving LTCI services among the slightly frail elderly, the physical fitness program 
is included in the new scheme.

Most of the model programs used some kinds of fitness machines, i.e, hip abductor and knee curl machine. In fact such programs proved the effectiveness of physical fitness machines for improving the mobility of aged peoples, although the study size was relatively small in most of the cases ${ }^{1,2)}$. However, there are pointed out several problems for the machine based program as follows.

At first, the number of participants is limited. Usually they use 5 different machines, by repeating exercise and rest, participants do 5 different activities consecutively. Because of this operative manner, the number of participants is limited around 10 in most of the cases.

Secondary, the program costs much, because it requires machines and at least 3 health professionals (nurse, PT, OT, physical trainer, etc).

Thirdly, as available places are limited, they need a transfer service in order to frequent such a program. It requires the additional cost.

Fourthly, it is rather difficult to maintain physical fitness level after the end of program, unless there are available follow-up programs.

In order to solve these problems, Kochi city health bureau has developed a non-machine based physical fitness program, so called "Active centenarian physical fitness program (Iki-iki hyaku-sai Taiso)"3,4). This program does not require any expensive machine and makes it possible for the elderly to continue physical fitness program in their residence. As most of the local governments are suffering from the shortage of budget and manpower, this kind of simple program will be very attractive.

In order to test the usefulness of "Active centenarian physical fitness program" in other regions, the authors have applied this program in an isolated island of Kagoshima. We will present the results of our field studies.

\section{Studied Population and Method}

\section{Studied population}

The studied populations are inhabitants of an isolated island of Kagoshima. The population is about 35,000 people and the aged 65 years old and more counts for $26 \%$ of total population (2000). Major industries are farming of sugarcane, sweet potato, rice and fruits, and dairy farming.
The participants were the slightly frail elderly more than 65 years old. The town office had distributed information about the physical fitness class through town papers and other medias. Most of the participants were recruited by the direct contact from public health nurses and care managers of the town

So far as the LTCI eligibility level is concerned, there were 1 care required level 1, 5 assistance required, and 12 non-eligible frail elderly. For sex distribution, men were 4 and women were 14 . The average age was $78.17 \pm 4.18$ years old (min: 71 , max: 85 years old).

\section{“Active centenarian physical fitness program} (Iki-iki hyaku-sai Taiso)"

The contents of "Active centenarian physical fitness program (Iki-iki hyaku-sai Taiso)" are as follows.

The warming up exercises continues about 15 minutes composing of: (1) Deep respiration (2) Shoulders side extending (3) Body twist (4) Movement of neck (5) Step (6) Exercise of articulation coaxes (7) Knees extending (8) Deep respiration.

The main exercises continues about 30 minutes composing of: (1) Raises arms to back (2) Raises arms to sideways (3) Bending and extending knees (4) Standing up from chair (5) Extending knees (6) Raising legs to back (7) Raising legs to horizontal.

For the main exercise, the participants use weight band. The weight bands ( $100 \mathrm{~g}$ per one weight) was put on the wrist and ankle, and the number of weight was increased when it was felt "It is too easy", it was continued by an untouched load when it was felt "It was easy", and it was decreased when it was felt "It is tight" by the self-evaluation after the exercise. The load has been adjusted from $0 \mathrm{~g}$ weight of the band unfitting to $700 \mathrm{~g}$ of the full fitting.

The cooling down exercise about 15 minutes (1) Shoulder exercise (2) Wrist and arm stretch (3) Stretch in back of thigh (4) Stretch of calf (5) Neck is turned right and left.

The participants exercised for 1 hour and half twice a week during 12 weeks from January to April 2006.

\section{Evaluation method}

The participants were evaluated at three days before the first exercises day and three days after the final days. The contents of evaluation were physical 
Table 1 Measurement of physical fitness

\begin{tabular}{|c|c|c|c|c|c|c|c|}
\hline & \multicolumn{2}{|c|}{ Mean \pm SD } & \multirow{2}{*}{ Probability } & \multirow{2}{*}{$\begin{array}{l}\text { Improve- } \\
\text { ment }\end{array}$} & \multirow{2}{*}{$\begin{array}{l}\text { No } \\
\text { change }\end{array}$} & \multirow{2}{*}{$\begin{array}{l}\text { Deteriora- } \\
\text { tion }\end{array}$} & \multirow{2}{*}{ Total } \\
\hline & Before & After & & & & & \\
\hline Sitting front stretch $(\mathrm{cm})$ & $31.9 \pm 9.7$ & $34.1 \pm 9.1$ & 0.156 & 8 & 0 & 7 & 15 \\
\hline Functional reach $(\mathrm{cm})$ & $30.7 \pm 5.1$ & $32.7 \pm 4.5$ & 0.173 & 10 & 0 & 5 & 15 \\
\hline $\begin{array}{l}\text { Knee joint progress } \\
\text { muscular power }(\mathrm{kg})\end{array}$ & $176.9 \pm 39.1$ & $200.0 \pm 52.5$ & $0.061^{\dagger}$ & 10 & 0 & 5 & 15 \\
\hline $\begin{array}{l}10 \text { m maximum walking } \\
\text { time (second) }\end{array}$ & $8.1 \pm 4.1$ & $8.1 \pm 5.0$ & $0.099^{\dagger}$ & 12 & 0 & 3 & 15 \\
\hline $\begin{array}{l}\text { Timed Up \& Go } \\
\text { (second) }\end{array}$ & $9.9 \pm 5.0$ & $8.8 \pm 4.8$ & $0.015 *$ & 11 & 0 & 4 & 15 \\
\hline $\begin{array}{l}\text { Standstill step for } \\
2 \text { minutes (step) }\end{array}$ & $103.3 \pm 14.4$ & $109.7 \pm 12.2$ & $0.041 *$ & 10 & 0 & 5 & 15 \\
\hline
\end{tabular}

${ }^{*} \mathrm{p}<0.05,{ }^{\dagger} \mathrm{p}<0.1$.

fitness test, questionnaire surveys on lifestyle, IADL and mental status.

Physical fitness test were sitting front stretch as flexibility, functional reach as balance, knee joint progress muscular power as lower limbs muscular power, $10 \mathrm{~m}$ maximum walking time as walking ability, timed up \& go as whole body cooperation, and two minutes standstill step as endurance. The measuring method followed the guideline of the Ministry of Education, Culture, Sports, Science and Technology5).

Lifestyle, Instrumental Activities of Daily Living (IADL), and the mental status were measured by the Kitakyushu City version of activity ability assessment (Appendix 1) ${ }^{6}$ ) and the revised edition of Frenchay Activities Index self-evaluation table (Appendix 2) ${ }^{7-9}$.

\section{Goal setting by ICF}

The International Classification of Functioning, Disability and Health (ICF) is WHO's framework for measuring health and disability at both individual and population levels. The ICF was officially endorsed by 191 WHO Member States in the Fifty-fourth World Health Assembly on 22 May 2001 (resolution WHA 54.21). ICF describes how people live with their health condition. ICF is a classification of health and health related domains that describe body functions and structures, activities and participation. The domains are classified from body, individual and societal perspectives.

In order to clarify the meaning of training on the participants lives, each participant was asked to set goals of training by ICF concepts. For example, a female aged (76 years old) set the target at participa- tion level as "I want to go to the grandchild in Osaka to meet," and the corresponding target at activity level as "to walk without cane, to cook by oneself, and etc".

\section{Statistical analysis}

Because of relatively small number of samples, we employed the non-parametric analyses in this study. Wilcoxon signed rank test was used for the comparison before and after exercises, and Spearman's rank-order correlation coefficient was used for the correlation analysis of change in evaluation of each item. The SPSS 14.0J for Windows (SPSS, Japan, and Tokyo) is used for the statistical work. Differences were considered statistically significant at $\mathrm{p}<0.05$ level.

All the subjects were informed about the purpose of study and its practical details before they gave their written consent to participate. This study was approved by the Ethics Committee of the University of Occupational and Environmental Health.

\section{Results}

Table 1 shows the results of physical fitness test. Timed up \& go test and two minutes standstill step test had improved with statistical significance after the program. Although there were no statistically significant changes, knee joint progress muscular power test, $10 \mathrm{~m}$ maximum walking time test, sitting front stretch test and functional reach test also showed improvement tendency.

Table 2 shows the result of questionnaire surveys on lifestyle, mental status and IADL. Only social role 
Table 2 Change in Lifestyle, Mental status, and IADL

\begin{tabular}{|c|c|c|c|c|c|c|}
\hline & & Improved & No change & Worsened & Total & Probability \\
\hline \multicolumn{7}{|c|}{ Kitakyushu City version activity ability assessment } \\
\hline \multirow[t]{2}{*}{ Lifestyle } & Rank sum & 24.5 & & 41.5 & & 0.446 \\
\hline & $\mathrm{N}$ & 5 & 4 & 6 & 15 & \\
\hline \multirow[t]{2}{*}{ Instrumental independency } & Rank sum & 22 & & 44 & & 0.326 \\
\hline & $\mathrm{N}$ & 3 & 4 & 8 & 15 & \\
\hline \multirow[t]{2}{*}{ Intellectual activeness } & Rank sum & 25 & & 3 & & $0.054 *$ \\
\hline & $\mathrm{N}$ & 6 & 8 & 1 & 15 & \\
\hline \multirow[t]{2}{*}{ Social role } & Rank sum & 15 & & 0 & & $0.034 * *$ \\
\hline & $\mathrm{N}$ & 5 & 10 & 0 & 15 & \\
\hline \multirow[t]{2}{*}{ Healthy feeling } & Rank sum & 55.5 & & 35.5 & & 0.478 \\
\hline & $\mathrm{N}$ & 7 & 2 & 6 & 15 & \\
\hline \multirow[t]{2}{*}{ Feelings } & Rank sum & 21.5 & & 14.5 & & 0.608 \\
\hline & $\mathrm{N}$ & 5 & 7 & 3 & 15 & \\
\hline \multicolumn{7}{|c|}{ Frenchay Activities Index Revised edition Self-evaluation table } \\
\hline \multirow[t]{2}{*}{ Indoor housework } & Rank sum & 19 & & 9 & & 0.380 \\
\hline & $\mathrm{N}$ & 4 & 8 & 3 & 15 & \\
\hline \multirow[t]{2}{*}{ Outdoor housework } & Rank sum & 17 & & 38 & & 0.280 \\
\hline & $\mathrm{N}$ & 4 & 5 & 6 & 15 & \\
\hline \multirow[t]{2}{*}{ Outdoor activity } & Rank sum & 46 & & 9 & & $0.058^{\dagger}$ \\
\hline & $\mathrm{N}$ & 7 & 5 & 3 & 15 & \\
\hline \multirow[t]{2}{*}{ Hobby } & Rank sum & 36.5 & & 8.5 & & $0.093^{\dagger}$ \\
\hline & $\mathrm{N}$ & 7 & 6 & 2 & 15 & \\
\hline \multirow[t]{2}{*}{ Work } & Rank sum & 7.5 & & 13.5 & & 0.516 \\
\hline & $\mathrm{N}$ & 3 & 9 & 3 & 15 & \\
\hline
\end{tabular}

Lifestyle: Breakfast, movement, sleep, and stress

Instrumental independency: Standing up from mat, getting on and off of pair of pants in standing up, falls, walking, going up and down in the stairs, and buses

Intellectual activeness: Sending card, using courier service, and reading books

Social role: Conversation with people other than family

Healthy feeling: Concern of health, Subjective health condition, and easiness in the sickness

Feelings: Tedious, new thing, and powerlessness

Indoor housework: Preparing main meals, washing up, washing clothes, light housework, and heavy housework

Outdoor housework: Local shopping, gardening, and household and car maintenance

Outdoor activity: Social outings, walking outside, driving, use of transportation, travel

Hobby: Actively pursing hobby, and reading books

Work: Gainful work

${ }^{*} \mathrm{p}<0.05,{ }^{\dagger} \mathrm{p}<0.1$.

had improved with statistics significant difference. Intellectual activeness, outdoor activity, and hobby activities also showed improvement tendencies, but statistically significant differences were not observed. Lifestyle, instrumental independency, subjective feeling of health, emotional status, indoor housework, outdoor housework, and work did not show any clear improvement tendency after the training program.

So far as the correlations among factors investigated are concerned, a statistically significant correlation was observed only between $10 \mathrm{~m}$ maximum walking time test and the social role $(\mathrm{r}=0.575$, $\mathrm{p}=0.025$ ). 


\section{Discussion}

In the current study, the functional improvement program of musculoskeletal system that does not use machine for the elderly was performed twice a week for 12 weeks. For the physical fitness test, improvement tendency was observed for timed up \& go test, two minutes standstill step test, knee joint progress muscular power test, and $10 \mathrm{~m}$ maximum walking time test. We have already reported effectiveness of machine based exercise among the frail elderly ${ }^{1)}$. The results of current study indicate that physical fitness training not using machine would have similar effects, as other previous literatures indicated ${ }^{10,11)}$.

Compared with the machine based program, "Active centenarian physical fitness program (Iki-iki hyaku-sai Taiso)" has lots of advantages for application in the community setting. At first, it does not require much resource. This characteristic is very important for the rural community that cannot prepare much budget for the health promotion program. Secondary, it is a simple program. Even for the aged who is not accustomed to sportive activities, it is easy to master the program. Thirdly, this program has possibility to become a community movement. The Kochi city office organizes the "Iki-iki Hyaku-sai Taiso" festival every year. Many local governments where the program is on going are invited to the festival. This means that the program will be a very useful tool of population approach.

After the training, the improvement tendency was observed in social role, intellectual activeness, outdoor activity, and hobby activity among the participants. So far as the life style was concerned, there were positive changes observed in our study. For example, a positive correlation was observed between $10 \mathrm{~m}$ maximum walking time and the social role. Katsura et al. reported that the total amount of steps was closely related to independency level of life among the elderly people ${ }^{12)}$.

In our past study about effect of physical fitness training on the lifestyle, the mental status, and IADL of the elderly there was no improvement observed ${ }^{1)}$. It is considered that the goal setting based on the ICF model has bridged the improvement of physical fitness level to that of participation level.

On the contrary, the improvement tendency was not observed in subjective feeling of health and mental status. Arai et al. also indicated that there was little effect of physical fitness training on the mental status of the elderly people ${ }^{13)}$. It might be that the training period is too short to influence on mental status. In the current study we have required for each participant to set the goal of "participation level of ICF" in order to clarify the meanings of physical fitness program. It was the first experience both for researchers and studied population to use the ICF concept for goal setting. This might be a possible reason for no effect of the physical fitness program on mental status.

So far as the causes of independency are concerned, fall is very important among the slightly frail elderly. In order to reduce the risk of fall, it is useful to improve the balance function of the elderly. For this purpose, many physical fitness classes have been organized in the community. Ono et al. have reported that the fall ratio decreased after the exercise class ${ }^{14}$. However, there was no clear improvement observed for balance function in our program. Kin et al. have organized the tai chi exercise class for the elderly and indicated that it is necessary to continue at least more than six months in order to improve the physical functions like balance, muscular power, mobility, and flexibility ${ }^{15}$. The exercise period of our research was three months, and it seems that the training period was too short to improve the balance level such as functional reach.

As mentioned above, in the case of physical training for the aged, importance of continuance of exercise has been indicated by several researchers. Takahashi et al. compared the increase of muscular power between the group with exercise twice a week during 6 months and the group with exercise once a week for one year. Interestingly, the effect was more apparent for the latter group. In addition, the group with twice a week exercise has decreased the activity in daily life ${ }^{16-18)}$. Hanaoka has examined the influence of intermittent period on the effect of physical fitness training ${ }^{17}$. He organized the exercise training once a week for four weeks, and then re-stared the class after 3 to 7 months during the three years. He reported that all items except for flexibility decreased and suggested that the intermittent exercise training would have a low level effectiveness on physical function of the elderly.

In our research, the staffs of the local government and the nursing facilities were asked to participate as a training staff, in order to master the methodology of physical fitness training. In this way we have tried to 
transfer the know-how in order to make it possible for local staffs to continue the exercise training in an isolated island after our research project. In fact, the local government is continuing the physical fitness program using the 6 community centre and 3 LTCI facilities in the town in 2006. We would like to investigate the effect of follow-up program and report it in the future literature.

\section{Conclusion}

1. Physical fitness training not using machines for the elderly, so called "Active centenarian physical fitness program (Iki-iki hyaku-sai Taiso)" had been applied in an isolated island of Kagoshima. Improvement was observed for most of the physical fitness tests.

2. So far as lifestyle, mental status and IADL were concerned, there were improvement observed in social role, intellectual activeness, outdoor activity, and hobby activity.

3. It is considered that the goal setting based on the ICF model has bridged the improvement of physical fitness level to that of participation level.

\section{Acknowledgement}

The authors are grateful to the Kochi City public health center, the inventor of "Active centenarian physical fitness program (Iki-iki hyaku-sai Taiso)". They are very kind to teach us how to organize the program and permit to apply it in the studied field.

The authors are also thankful to staffs of the Nakatane town office and Nakatane Health center, and all the participants for their assistance.

This research was funded by grants in 2005 from Sompo Japan Research Institute.

\section{References}

1) Yano J, Ibayashi H, Nishiyama T, et al.: Functional improvement program of musculoskeletal system of the elderly in an isolated island of Kagoshima Prefecture. Journal of University of Occupational and Environmental Health 28, 229-237 (2006) (in Japanese).

2) Satomi K, Konno K, Aizawa J, et al.: Effectiveness of a fitness program for the elderly that focuses on strength training. Health Evaluation and Promotion
32, 225-229, (2005) (in Japanese).

3) Yoshinaga $\mathrm{T}$ : Approach of Kochi City version strength training "Active centenarian physical fitness program (Iki-iki hyaku-sai Taiso)", The approach of the nursing care prevention in which not only a high risk measures but also the resident can participate. GP net 52, 16-22 (2005) (in Japanese).

4) Yoshinaga $T$ : ADL prevention programs in the community, "Active centenarian physical fitness program (Iki-iki hyaku-sai Taiso)" that has expanded to whole area of city. The Japanese Journal of Total Care 15, 18-23, (2005) (in Japanese).

5) Ministry of Education, Culture, Sports, Science and Technology. New physical strength test guideline (for 65-70-years old) (2000) (in Japanese). (http://www.mext.go.jp/a_menu/sports/stamina/ 0304901.htm)

6) Matsuda S: Report on the effective preventive ADL care. Kitakyushu-city (2005) (in Japanese).

7) Suenaga $H$, Miyanaga $K$, Chisaka $H$, et al.: Modified version of the self-rating frenchay activities index and its reliability and validity. Japanese Journal of Occupational Medicine and Traumatology 48, 55-60, 2000 (in Japanese).

8) Hachisuka K, Chisaka H, Kawazu T, et al.: Applied activities of daily living and its standard value determined according to frenchay activities index scores for randomly sampled middle and advanced age people living at home. The Japanese Journal of Rehabilitation Medicine 38, 287-295 (2001) (in Japanese).

9) Shiratsuchi M, Saeki S, Hachisuka K: Japanese version of the self-rating frenchay activities index and its clinical application and standard values. Sogo Rehabilitation 27, 469-474 (1999) (in Japanese).

10) Nishida $Y$, Hiwatari $M$, Maruyama $H$ : Effect of low-intensity exercise training program of 12 weeks intended for elderly people who are imprisoned to facilities, Influence on autonomous nervous system activity and physical function. The Japanese Journal of Physical Therapy 40, 585-590 (2006) (in Japanese).

11) Kitayuguchi J, Minami S, Masuo Y, et al.: Effects of regular exercise for over 1.5 years on fitness and skeletal muscle mass in middle-aged and elderly people. Journal of Physical Education \& Medicine 7, 19-23, (2006) (in Japanese).

12) Katsura $T$, Hosono A: Characteristic of independent 
moving ability in elderly residents, Comparison of physical factors relating to walking strides between young-old residents and old-old residents. Journal of Japan Health Medicine Association, 14, 16-23 (2006) (in Japanese).

13) Arai $T$, Obuchi $S$, Henmi $O$, et al.: The evaluation of relationships between psychological factors and the effects of exercise intervention on physical functions in the community-dwelling frail elderly. Rigaku ryohogaku 33, 118-125 (2006) (in Japanese).

14) Ono K, Otsuki T, Awano N, et al. Effect of the exercise therapy for elderly people to prevent falls. Tohoku journal of orthopedics and traumatology 50 , 23-26 (2006) (in Japanese).

15) Kin SK, Kurosawa K: Effect of tai chi on improving physical performance and preventing falling in community-dwelling old women. Rigakuryouhou Kagaku 21, 275-279 (2006) (in Japanese).

16) Takahashi H, Tsuboyama M, Kumagai $T$, et al.: Effects of group instruction for improving physical activity in the elderly as supported by a local government. Journal of the Faculty of Nursing, Iwate Prefecture University 7, 51-58 (2005) (in Japanese).

17) Hanaokawa $M$ : The effects of a health promotion program on physical fitness in the elderly. Ishikawa Journal of Nursing 3, 5-10 (2005) (in Japanese).

18) Yamamoto M, Shin $T$, Nakazono $T$, et al.: The effects of an exercise program for the female elderly in the community. Journal of University of Occupational and Environmental Health 27, 339-348 (2005) (in Japanese). 
Appendix 1. Kitakyushu City version activity ability assessment

\section{Date:}

Name

Kitakyushu City Version Activity Ability Assessment

I Lifestyle (Please check the applying one.)

- Breakfast

$\square$ Never

$\square$ I cannot sleep a lot of days.

Sleep $\square$ Occasionally sleep a lot.

$\bullet$ Exercise

$\square$ Never

Stress

$\square$ I feel it.

$\square$ I can sleep soundly. $\square$ Occasionally

$\square$ I rarely feel it. $\square$ Every day

$\square$ Sleeping time is short.

$\square$ Rarely

$\square$ I feel it a little.
Regularly

$\square$ I don't feel it.

II About the state of the mind and body in daily life (catching)

(Instrumental independent)

1 Can you stand up from the tatami?

2 Can you put the pair of pants on standing?

3 Do you stumble or slip in the house?

4 How much can you walk?

5 Can you go up and down the stairs at the station by yourself?

6 Can you do getting on and off of the bus and the train?

(Intellectual activeness)

7 Can you write the sending card of the courier service?

8 Are you reading newspaper, book, or magazine (Even one is acceptable)?

(Social role)

9 Do you have the chance to talk with the people other than the family?

(Healthy feeling)

10 Are you interested in aticle and TV program of health?

11 How do you think of your health condition?

12 Do you think that you tend to become sick compared with other people?

III Your current feelings. (Please check the applying one.)

- Do you often think that every day is tedious?

$\square$ Yes

$\square$ Occasionally

$\square$ No

- Do you think that you want to stay home than go out or do something new?

Do you feel a powerless feeling?

$\square$ Yes $\square$ Occasionally

$\square$ Yes $\quad \square$ Occasionally

$\square$ No 
Appendix 2. Frenchay Activities Index Revised edition Self-evaluation table

In the last three month how often have you undertaken:

1 Preparing main meals

$\square$ Never

$\square$ Unusually

$\square 1-3$ times a week

$\square$ Most days

2 Washing up

$\square$ Never

$\square$ Unusually

$\square$ 1-3 times a week

$\square$ Most days

3 Washing clothes

$\square$ Never $\square$ Unusually

$\square$ 1-3 times a month

$\square$ Most days

4 Cleaning and order

$\square$ Never

$\square$ Unusually

$\square$ 1-3 times a month

$\square$ Most days

5 Heavy housework

$\square$ Never

$\square$ Unusually

$\square$ 1-3 times a month

$\square$ Most days

6 Local shopping

$\square$ Never

$\square$ Unusually

$\square$ 1-3 times a month

$\square$ Most days

7 Social outings

$\square$ Never

$\square$ Unusually

$\square$ 1-3 times a month

$\square$ Most days

8 Walking outside more than 15 minutes $\square$ Never

$\square$ Unusually

$\square$ 1-3 times a month

$\square$ Most days

9 Actively pursing hobby

$\square$ Never

$\square$ Unusually

$\square$ 1-3 times a month

$\square$ Most days

10 Driving a car/going on a bus

$\square$ Never

$\square$ Unusually

$\square$ 1-3 times a month

$\square$ Most days

11 Travel outings/car rides

$\square$ Never

$\square$ Unusually

$\square$ 1-3 times a month

$\square$ Most days

12 Gardening

$\square$ Never

$\square$ Light

$\square$ Moderate

$\square$ All necessary

13 Houshold/car maintenance

$\square$ Never

$\square$ Light

$\square$ Moderate

$\square$ All necessary

14 Reading books

$\square$ None

$\square$ Unusually

$\square$ One in a month

$\square$ More than 2 in a month

15 Gainful work

$\square$ None

$\square$ 1-9 hours/week

$\square$ 10-30 hours/week

$\square$ Over 30 hours/week 